\title{
A loop-mediated isothermal amplification assay for the visual detection of duck circovirus
}

\author{
Liji Xie, Zhixun Xie*, Guangyuan Zhao, Jiabo Liu, Yaoshan Pang, Xianwen Deng, Zhiqin Xie, Qing Fan and Sisi Luo
}

\begin{abstract}
Background: Duck circovirus (DuCV) infection in farmed ducks is associated with growth problems or retardation syndromes. Rapid identification of DuCV infected ducks is essential to control DuCV effectively. Therefore, this study aims to develop of an assay for DuCV to be highly specific, sensitive, and simple without any specialized equipment.

Methods: A set of six specific primers was designed to target the sequences of the Rep gene of DuCV, and A loop-mediated isothermal amplification (LAMP) assay were developed and the reaction conditions were optimized for rapid detection of DuCV.

Results: The LAMP assay reaction was conducted in a $62^{\circ} \mathrm{C}$ water bath condition for $50 \mathrm{~min}$. Then the amplification products were visualized directly for color changes. This LAMP assay is highly sensitive and able to detect twenty copies of DuCV DNA. The specificity of this LAMP assay was supported by no cross-reaction with other duck pathogens.
\end{abstract}

Conclusion: This LAMP method for DuCV is highly specific and sensitive and can be used as a rapid and direct diagnostic assay for testing clinical samples.

Keywords: Duck circovirus, Loop-mediated isothermal amplification, Visual detection

\section{Background}

The duck circovirus (DuCV) was reported initially in Germany in 2003, which was detected from two female 6-week-old female Mulard ducks with feathering disorders, poor body condition, immunosuppression and low weight [1]. Subsequently, DuCV infection was confirmed in Hungary [2], Taiwan [3], United States [4] and Mainland China [5,6]. Histopathologic examination of the bursa of Fabricius (BF) demonstrated lymphocyte depletion, necrosis and histiocytosis. DuCV was detected in Mulard ducks, as well as other duck species of Muscovy, Mule, Cherry Valley, Pekin and Pockmark ducks [4-8].

$\mathrm{DuCV}$ is a small (15-16 $\mathrm{nm}$ in diameter), round, nonenveloped, single-stranded DNA virus with a circular genome of approximately $1.9 \mathrm{~kb}$. The genome contains two major open reading frames (ORFs), designated ORF V1 (Rep gene) and ORF C1 (Cap gene) [1].

\footnotetext{
* Correspondence: xiezhixun@126.com Department of Biotechnology, Guangxi Key Laboratory of Animal Vaccines and Diagnostics, Guangxi Veterinary Research Institute, 51 Youai North Road, 530001 Nanning, China
}

Virus isolation is a fundamental diagnostic method, but no in vivo culture system is yet available for the propagation of $\mathrm{DuCV}[9,10]$. Other diagnostic techniques, such as conventional polymerase chain reaction (PCR) [2], nested PCR [11], real-time PCR [2,10], ELISA [9] and in situ hybridization (ISH) have been developed. However, these techniques usually need more time and require specialized equipment. For example, PCR requires agarose gel analysis for the detection of amplification products and must be performed in specialized laboratories and ISH requires several days to complete the assay.

Recently, a new technique known as loop-mediated isothermal amplification (LAMP) has been described [12]. It can be used to amplify specific target DNA sequences with high sensitivity and, advantageously, it can be completed within 30 to $60 \mathrm{~min}$ under isothermal conditions, without the need of a thermal cycler and/or specialized laboratory [12]. This technique eliminates the heat denaturation step for the DNA synthesis used in conventional PCR and relies instead on auto-cycling strand displacement DNA synthesis, which is achieved by a DNA 
polymerase with high strand displacement activity and a set of specially designed primers: two inner primers and two outer primers. Another important feature of LAMP is the color change, which is visible to the naked eye and results can be obtained in $60 \mathrm{~min}$ at a constant set temperature. The LAMP assay has been previously used to successfully detect other viral pathogens [13-19]. The objective of the present study is to develop and optimize a LAMP assay for the detection of DuCV.

\section{Methods}

\section{Ethics statement}

This study was approved by the Animal Ethics Committee of the Guangxi Veterinary Research Institute. The institute did not issue a number or ID to this animal study, because the studied ducks are not an endangered or protected species. Sample collection was conducted based on the protocol issued by the Animal Ethics Committee of the Guangxi Veterinary Research Institute.

\section{Virus strains and DNA/RNA extraction}

The DuCV strains and the other duck pathogen strains used in this study are listed in Table 1. The genomic DNA/RNA was extracted from $200 \mu \mathrm{L}$ of the viruses listed in Table 1 using an EasyPure Viral DNA/RNA kit (Transgen, Beijing, China), according to the manufacturer's protocol. The DNA and RNA were eluted with $50 \mu \mathrm{L}$ elution buffer. The concentrations of total DNA and RNA were measured by UV spectrophotometry (Beckman UV800, Beckman Coulter, USA). DNA and RNA samples were stored immediately at $-70^{\circ} \mathrm{C}$ until required.

\section{Primer design for the LAMP assay}

Primer design for DuCV LAMP was based on the published Rep gene sequence of the DuCV strain 33753-52 (GenBank, accession no. DQ100076). The DuCV strain 33753-52 sequence was aligned with the available sequences of twenty viral isolates to identify the conserved regions.

A set of six specific primers for the DuCV LAMP assay was designed using LAMP primer design software, Primer Explorer V4 (http://primer explorer.jp/elamp4.0.0/index. html). The LAMP primer set comprised two outer primers (forward primer F3 and backward primer B3), two inner primers (forward inner primer FIP and backward inner primer BIP) and two loop primers (forward loop F and backward loop B). The outer primers (F3 and B3) were used in the initial steps of the LAMP reactions but later, during the isothermal cycling, only the inner primers were used for strand displacement DNA synthesis. The loop primers were designed to accelerate the amplification reaction as previously described [17]. Since each inner primer (FIP $(\mathrm{F} 1 \mathrm{c}+\mathrm{F} 2)$ and BIP $(\mathrm{B} 1 \mathrm{c}+\mathrm{B} 2))$ consists of two sequences, targeting two specific sites, the six primers consequently
Table 1 Pathogens strains and LAMP assay results

\begin{tabular}{ccc}
\hline $\begin{array}{l}\text { Pathogen strain/other } \\
\text { duck pathogens }\end{array}$ & Source & Virus information \\
\hline DuCV (GX1006) & GVRI & $\begin{array}{c}\text { Original positive tissue } \\
\text { specimen }\end{array}$ \\
DuCV (GX1008) & GVRI & $\begin{array}{c}\text { Original positive tissue } \\
\text { specimen }\end{array}$ \\
DuCV (GX1104) & GVRI & $\begin{array}{c}\text { Original positive tissue } \\
\text { specimen }\end{array}$ \\
DuCV (GX1105) & GVRI & $\begin{array}{c}\text { Original positive tissue } \\
\text { specimen }\end{array}$ \\
DuCV (GX1209) & GVRI & $\begin{array}{c}\text { Original positive tissue } \\
\text { specimen }\end{array}$ \\
DuCV (GX1208) & GVRI & Original positive tissue \\
specimen
\end{tabular}

Muscovy duck parvovirus CIVDC Duck embryo cultured virus (AV238)

$\begin{array}{lcc}\begin{array}{l}\text { Avian influenza virus } \\ \text { subtype H5 (Inactivated) }\end{array} & \text { HVRI } & \text { Chick embryo cultured virus } \\ \begin{array}{l}\text { Avian influenza virus } \\ \text { subtype H9 }\end{array} & \text { GVRI } & \text { Chick embryo cultured virus } \\ \text { Duck plague virus } & \text { GVRI } & \text { Duck embryo cultured virus } \\ \begin{array}{l}\text { Duck paramyxovirus } \\ \text { Gosling parvovirus }\end{array} & \text { GVRI } & \text { Duck embryo cultured virus } \\ \text { Duck hepatitis virus } & \text { CIVDC } & \text { Duck embryo cultured virus } \\ \end{array}$

(AV2111)

Negative tissue (Duck spleen and liver)

GVRI = Guangxi Veterinary Research Institute, China

CIVDC = China Institute of Veterinary Drugs Control, China.

HVRI = Harbin Veterinary Research Institute, China.

Positive $=+$; Negative $=-$.

recognized eight sites on the target sequence specific to the Rep gene segment. The details of the primers are shown in Table 2. All primers were purchased from Invitrogen (Guangzhou, China).

\section{Optimization of the DuCV LAMP conditions}

The DuCV LAMP assay was performed in tubes containing 10× Thermopol $^{\circledR}$ Reaction Buffer (New England

Table 2 Oligonucleotide primers used for RT-LAMP assay

\begin{tabular}{lll}
\hline Primer name & Sequence (5'-3') & Genome position \\
\hline FIP = F1C + F2 & TTCAGGAATCCCTGAAGGTG- & F1c,203-222, \\
& ATCGTCGGMGAGGAVAGG & F2,167-185 \\
BIP = B1C+B2 & GCGMGAGCTGCCGCCCT- & B1c,236-252, \\
& TCTTCVTCAGATCCCCGG & B2,292-309 \\
F3 & AGTTBTGCACGCTCGACAAT & $135-154$ \\
B3 & GTCGACTCTTTGGMGCAATA & $320-339$ \\
LoopF & AGGYGTVCCVTTCGCGC & $186-202$ \\
LoopB & AGGAAGAGCCTGGCTCTC & $268-285$ \\
\hline
\end{tabular}

Genome position according to the DuCV complete genome sequence (GenBank accession no. DQ100076).

Abbreviations are as follows: $\mathrm{M}=\mathrm{A}$ or $\mathrm{C} ; \mathrm{V}=\mathrm{A}$ or $\mathrm{C}$ or $\mathrm{G} ; \mathrm{B}=\mathrm{T}$ or $\mathrm{G}$ or $\mathrm{C}$. 
Biolabs, Beijing, China), Bst DNA polymerase (large fragment; New England Biolabs), dNTPs (Takara, Dalian, China), primers, betaine (Sigma-Aldrich), $\mathrm{MgSO}_{4}$ (SigmaAldrich), calcein (International Laboratory, USA), $\mathrm{MnCl}_{2}$ (International Laboratory, USA), template DNA/RNA and nuclease-free water. Based on the previous studies, different combinations of various concentrations of each component (dNTPs $(0.4 \mathrm{mmol} / \mathrm{L} \sim 1.6 \mathrm{mmol} / \mathrm{L})$, betaine $(0.8 \mathrm{mmol} / \mathrm{L} \sim 1.4 \mathrm{mmol} / \mathrm{L}), \mathrm{MgSO}_{4}(2 \mathrm{mmol} / \mathrm{L} \sim 9 \mathrm{mmol} /$ L) were tested for amplification efficiency. The amplification reaction was performed in a thermal block between $59^{\circ} \mathrm{C}$ to $65^{\circ} \mathrm{C}$ within 40 to $80 \mathrm{~min}$, to ascertain the optimal incubation temperature and time. At the end of each incubation period, the reaction was terminated by heating at $80^{\circ} \mathrm{C}$ for $5 \mathrm{~min}$. All of the experiments were repeated three times.

\section{Analysis of DuCV LAMP products}

For a visual inspection of the LAMP assay products, fluorescence reagents (calcein and $\mathrm{MnCl}_{2}$; International Laboratory) were added to the reaction mixture before amplification and a color change of the reaction mixture was noted upon successful amplification. Samples that turned green were considered positive, while samples that remained orange were considered negative. Alternatively, $3 \mu \mathrm{L}$ of the DuCV LAMP products were analyzed by $1.5 \%$ agarose gel electrophoresis. The presence of a smear or a pattern of multiple bands with different molecular weights indicated a positive result [13].

\section{Evaluation of DuCV LAMP assays}

To evaluate the specificity of the assay, DNA/RNA samples extracted from different virus strains including DuCV, Muscovy duck parvovirus, avian influenza virus subtypes $\mathrm{H} 5$ and H9, duck plague virus, duck paramyxovirus, Gosling parvovirus and duck hepatitis virus were tested by the DuCV LAMP assay (Table 1). The detection limit of the LAMP to DuCV was assessed and compared with conventional PCR [5] using a series of tenfold dilutions of the DuCV template.

Briefly, DNA extracted from the DuCV strain GX1006 was used in the PCR reaction to amplify the Rep gene. The amplified product of the Rep gene was cloned into the pMD18-T cloning vector (TaKaRa, Dalian, China) according to the manufacturer's directions. The recombinant plasmids were sequenced. The sequence data were analyzed using DNASTAR software and were compared with the corresponding sequence data in GenBank. The copy number was calculated according to the following formula: (copies $/ \mu \mathrm{L}=6 \times 10^{23} \times \mathrm{DNA}$ concentration, $\mathrm{g} / \mu \mathrm{L}) /$ molecular weight, $\mathrm{g} / \mathrm{mol}$, as described by Xie et al. [20]. A series of ten-fold dilutions $\left(1 \times 10^{7}\right.$ to $1 \times 10^{\circ}$ copies $/ \mu \mathrm{L}$ ) were used to assess the sensitivity of the DuCV LAMP assay.

\section{Detection of clinical samples by DuCV LAMP assay}

A total of 181 clinical samples were collected from each sampling point (Nanning, Yulin, Hengxian, Ningming, Shanglin, Dongxing and Liuzhou) on commercial duck farms in Guangxi Province, China (Table 3). Spleen and liver $(0.1 \mathrm{~g})$ tissues were homogenized in $500 \mu \mathrm{L}$ sterile saline, centrifugation at $12,000 \mathrm{~g}$ for $15 \mathrm{~min}$, and then $200 \mu \mathrm{L}$ of the supernatant were used to extract DNA by using an EasyPure Viral DNA/RNA kit (Transgen, Beijing, China), according to the manufacturer's protocol. The extracted DNAs were tested by both the DuCV LAMP assay and real-time PCR as previously described by Fringuelli et al. [2].

\section{Results}

\section{DuCV LAMP assay}

After optimization of the reaction conditions, the DuCV LAMP assay was carried out in a $25 \mu \mathrm{L}$ reaction mixture

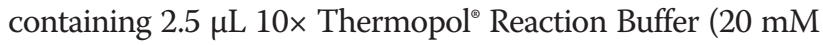
Tris-HCl, $10 \mathrm{mM}\left(\mathrm{NH}_{4}\right)_{2} \mathrm{SO}_{4}, 10 \mathrm{mM} \mathrm{KCl}, 2 \mathrm{mM} \mathrm{MgSO}$, $0.1 \%$ Triton X-100), $8 \mathrm{U}$ Bst DNA polymerase, $1 \mathrm{mmol} / \mathrm{L}$ betaine, $7 \mathrm{mmol} / \mathrm{L} \mathrm{MgSO}_{4}, 1.4 \mathrm{mmol} / \mathrm{L}$ dNTPs, $0.2 \mathrm{mmol} /$ L F3 primer, $0.2 \mathrm{mmol} / \mathrm{L} \mathrm{B} 3$ primer, $0.8 \mathrm{mmol} / \mathrm{L}$ forward loop (LF) primer, $0.8 \mathrm{mmol} / \mathrm{L}$ backward loop (LB) primer, $1.6 \mathrm{mmol} / \mathrm{L}$ forward inner primer (FIP), $1.6 \mathrm{mmol} / \mathrm{L} \mathrm{back}$ ward inner primer (BIP), $25 \mathrm{mmol} / \mathrm{L}$ calcein, $0.5 \mathrm{mmol} / \mathrm{L}$ $\mathrm{MnCl}_{2}, 2 \mu \mathrm{L}$ template DNA and $\mathrm{dH}_{2} \mathrm{O}$ to make the final volume up to $25 \mu \mathrm{L}$. The initial color of the reaction solution, prior to amplification, was orange. The optimal reaction time and incubation temperature were found to be $50 \mathrm{~min}$ at $62^{\circ} \mathrm{C}$.

\section{Specificity and sensitivity of DuCV LAMP assay}

The optimized DuCV LAMP assay was used to specifically amplify six Guangxi field DuCV strains. Test results (Figure 1A and B) showed that this technique exhibited no cross-reactivity with other avian viral pathogens tested including Muscovy duck parvovirus, Avian influenza virus

Table 3 Detection results of clinical samples by DuCV LAMP assay

\begin{tabular}{|c|c|c|c|c|}
\hline \multirow{2}{*}{$\begin{array}{l}\text { Location of } \\
\text { samples }\end{array}$} & \multicolumn{2}{|c|}{ LAMP } & \multicolumn{2}{|c|}{ Real-time PCR } \\
\hline & $\begin{array}{l}\text { Positive } \\
\text { samples/total } \\
\text { samples }\end{array}$ & $\begin{array}{l}\text { Positive } \\
\text { rate }\end{array}$ & $\begin{array}{l}\text { Positive } \\
\text { samples/total } \\
\text { samples }\end{array}$ & $\begin{array}{l}\text { Positive } \\
\text { rate }\end{array}$ \\
\hline Nanning & $5 / 29$ & $17.24 \%$ & $5 / 29$ & $17.24 \%$ \\
\hline Yulin & $4 / 77$ & $5.19 \%$ & $4 / 77$ & $5.19 \%$ \\
\hline Hengxian & $0 / 7$ & $0 \%$ & $0 / 7$ & $0 \%$ \\
\hline Ningmeng & $0 / 13$ & $0 \%$ & $0 / 13$ & $0 \%$ \\
\hline Shanglin & $1 / 38$ & $2.63 \%$ & $1 / 38$ & $2.63 \%$ \\
\hline Dongxing & $1 / 11$ & $9.09 \%$ & $1 / 11$ & $9.09 \%$ \\
\hline Liuzhou & $0 / 6$ & $0 \%$ & $0 / 6$ & $0 \%$ \\
\hline Total & 11/181 & $6.08 \%$ & $11 / 181$ & $6.08 \%$ \\
\hline
\end{tabular}




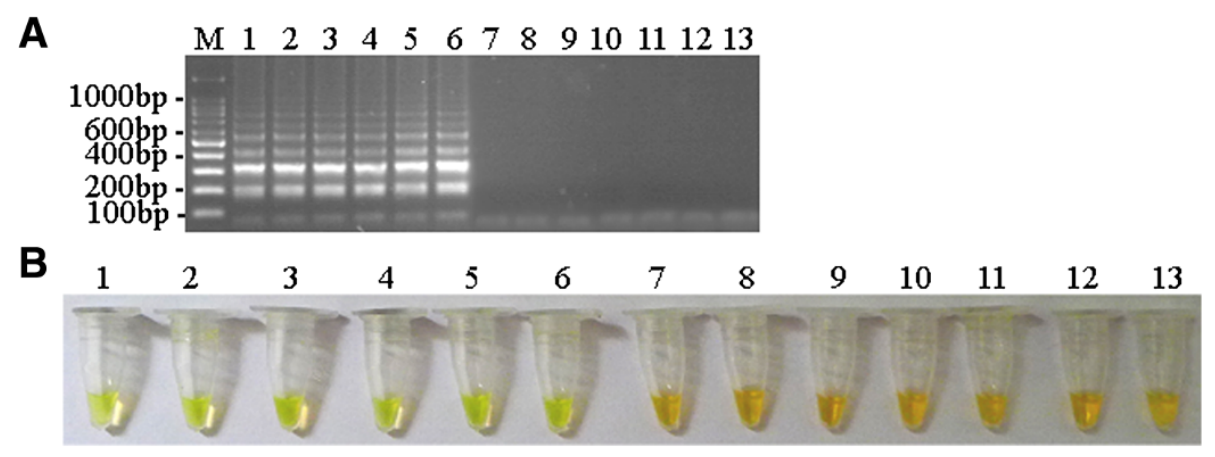

Figure 1 Specificity of DuCV LAMP assay. (A) Agarose gel electrophoresis of the LAMP products. M, 100 bp DNA ladder. (B) Visualization of the LAMP products. The numbers in (A) and (B) represent DuCV strains and the negative controls used in the specificity test. 1, DuCV GX1006; 2, DuCV GX1008; 3, DuCV GX1104; 4, DuCV GX1105; 5, DuCV GX1209; 6, DuCV GX1208; 7, Muscovy duck parvovirus AV238; 8, Avian influenza virus subtype H5; 9, Avian influenza virus subtype H9; 10, duck plague virus; 11, duck paramyxovirus; 12, Gosling parvovirus; 13, duck hepatitis virus AV2111.

subtype H5, Avian influenza virus subtype H9, Duck plague virus, Duck paramyxovirus, Gosling parvovirus and Duck hepatitis virus. Six DuCV field strains were tested by the DuCV LAMP assay and all final products of the LAMP assay yielded a positive green color (Figure 1B, lanes 1 to 6) and showed a typical DNA ladder pattern after 1.5\% agarose gel electrophoresis (Figure 1A, lanes 1 to 6). The products of the DuCV LAMP assay for the other avian viral pathogens remained negative orange color (no color change) (Figure 1B, lanes 7 to 13); furthermore, the other viral pathogens lacked the typical DNA ladder pattern, showing amplification did not occur (Figure 1A, lanes 7 to 13).

The sensitivity of the DuCV LAMP assay was then determined and compared with that of conventional PCR in parallel. As shown in Figure 2A, the detection limit of the DuCV LAMP assay is twenty copies (Figure 2A and B).
However, the detection limit of conventional PCR was $2 \times$ $10^{3}$ copies (Figure 3). This indicates that the sensitivity of the DuCV LAMP assay was 100-fold higher than that of conventional PCR. Our results showed that the DuCV LAMP assay is highly specific, sensitive and superior to the conventional PCR for the detection of DuCV.

\section{Detection of clinical samples by DuCV LAMP assay}

The UCV LAMP assay was used to test 181 clinical samples, which were also tested by real-time PCR for a comparison of the two assays. Eleven duck samples (6.08\%) were tested positive and 170 (93.92\%) were tested negative by both methods (Table 3). The DuCV LAMP and realtime PCR yielded $100 \%$ of agreement in testing these samples. However, DuCV LAMP was noted to be a quicker, easier and more cost-efficient method compared to realtime PCR.

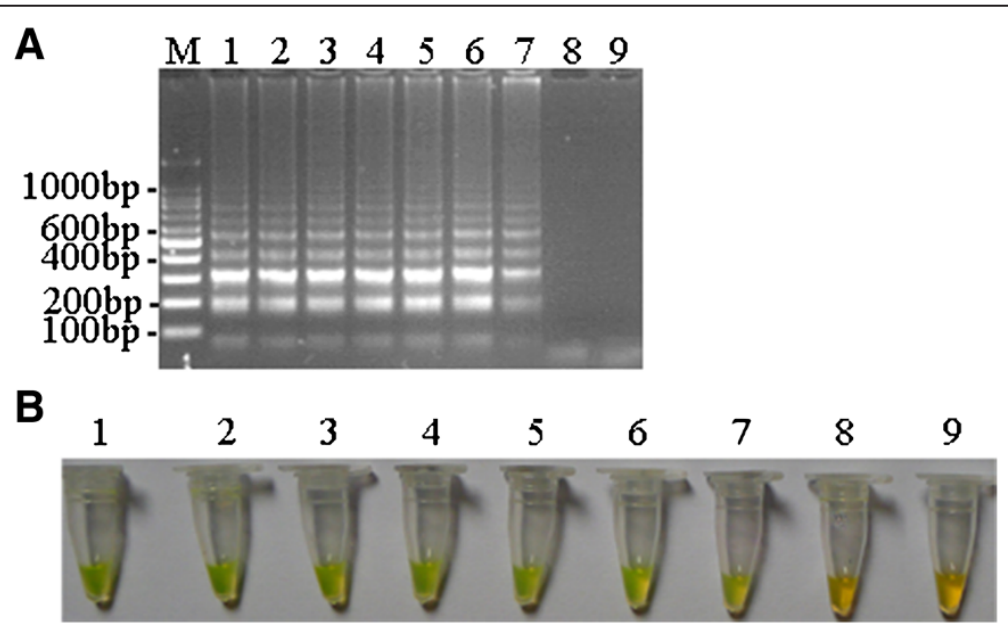

Figure 2 Sensitivity of the DuCV LAMP assay. (A) Agarose gel electrophoresis of the LAMP products. M, 100 bp DNA ladder. (B) Visualization of the LAMP products. Labels: $1,2 \times 10^{7}$ copies/tube; $2,2 \times 10^{6}$ copies/tube; $3,2 \times 10^{5} \mathrm{copies} /$ tube; $4,2 \times 10^{4}$ copies/tube; $5,2 \times 10^{3} \mathrm{copies} /$ tube; $6,2 \times 10^{2}$ copies/tube; 7, 20 copies/tube; 8,2 copies/tube; 9 , negative control. 


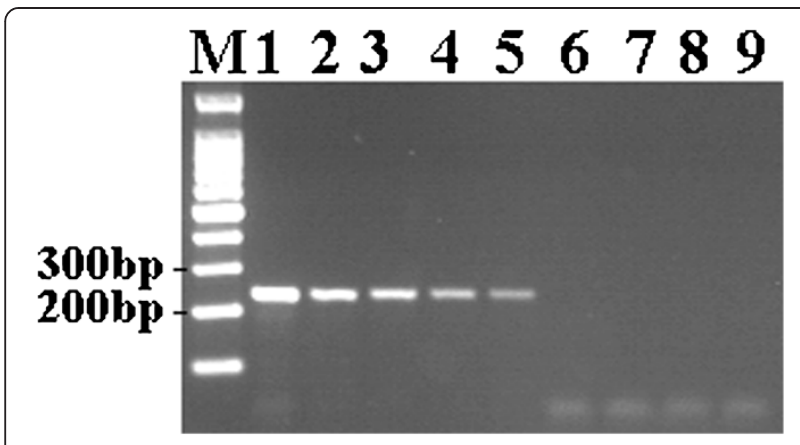

Figure 3 Sensitivity of conventional PCR. M, 100 bp DNA ladder; $1,2 \times 10^{7}$ copies/tube; $2,2 \times 10^{6}$ copies/tube; $3,2 \times 10^{5}$ copies/tube; 4, $2 \times 10^{4}$ copies/tube; $5,2 \times 10^{3}$ copies/tube; $6,2 \times 10^{2}$ copies/tube; 7, 20 copies/tube; 8,2 copies/tube; 9 , negative control.

\section{Discussion}

DuCV can cause feathering disorders, poor body condition, immunosuppression and low weight in ducks [1]. Consequently, the development of a rapid, simple and sensitive detection method for DuCV is essential.

In this study, a set of six primers targeting the Rep gene segment of DuCV were designed and the reaction conditions for LAMP were optimized through repeated experiments. The concentrations of each reaction reagent, i.e., $\mathrm{MgSO}_{4}$, betaine, dNTP, Bst DNA polymerase, calcein and $\mathrm{MnCl}_{2}$, can influence the amplification efficiency of the LAMP assay, which subsequently affects the fluorescence emission of the resulting solution. Therefore, it is necessary to optimize the reaction system to obtain the appropriate reagent concentrations, reaction temperature and amplification time. The results of the specificity tests indicated that the DuCV LAMP assay can successfully detected the DuCV field strains and showed no crossreaction with other viral pathogens. The established DuCV LAMP assay has several advantages in compared with conventional PCR. First, the detection limit of the DuCV LAMP assay is twenty copies, which is 100-fold higher than that of conventional PCR. Secondly, the amplification reaction of DuCV LAMP assay can be accomplished in a conventional laboratory water bath for $50 \mathrm{~min}$ and does not require a PCR machine or any other specialized equipment. Thirdly, the results can be inspected immediately and the color change is visible to the naked eye, which makes a rapid and easy determination of the test result without the need of electrophoresis analysis.

Nevertheless, the main challenge in the development of a DuCV LAMP assay is the hurge genetic heterogeneity of this virus $[4,18,21]$, with FIP and BIP being the most important primers in the LAMP assay that need to be conserved across the many strains. Another significant challenge in the development of a DuCV LAMP assay is its high amplification rate, which can result in potential cross-contamination issues. To investigate this issue, we added a dye (calcein with $\mathrm{MnCl}_{2}$ ) into the reaction system before the amplification in order to eliminate the chance of contamination. Prior to amplification, calcein combines with the manganese ions $\left(\mathrm{Mn}^{2+}\right)$ and the reaction solution turns orange. When the positive LAMP amplification reaction proceeds, the generated pyrophosphate ions remove the manganese ions $\left(\mathrm{Mn}^{2+}\right)$ from calcein, resulting in the emission of fluorescence from calcein. The free calcein may then combine with magnesium ions $\left(\mathrm{Mg}^{2+}\right)$ in the reaction mixture, leading to stronger fluorescence emission [22]. By the way, after the positive LAMP amplification reaction proceeds, the generated pyrophosphate ions combine with manganese ions $\left(\mathrm{Mn}^{2+}\right)$, and generate manganous pyrophosphate. By centrifuge, the manganous pyrophosphate precipitated at the bottom of the tube (white sediment at the bottom of the tube). And the negative LAMP did not have the white sediment. The generated manganous pyrophosphate is another way to determine the LAMP result by the white sediment besides examination of the color by naked eye.

A LAMP assay for Goose circovirus detection has been previously reported [23], but the sequence of the Goose circovirus and DuCV was different. To our knowledge, this is the first study to explore the use of DuCV LAMP technology in a diagnostic test for DuCV. The method and analysis is simple, specific, sensitive and rapid, furthermore, it can be used to detect DuCV in clinical samples.

\section{Conclusions}

A simple, rapid, highly sensitive and specific DuCV LAMP assay for the detection of DuCV has been developed and established in our present study. This technique has the potential to be applied in clinical or field conditions as it does not require the use of sophisticated equipment.

\section{Competing interests}

The authors declare that they have no competing interests.

\section{Authors' contributions}

$L X$ and $Z X$ designed the experiments. $G Z$ and $J L$ prepared the RNA/DNA samples. LX designed the primers and optimized conditions of the LAMP assay. $L X, X D, Z X, Q F, S L$ carried out the experiments shown in Figures 1, 2, 3 and in Table 3. GZ performed the data analysis. LX wrote the manuscript. All authors reviewed and approved the final version of the manuscript.

\section{Acknowledgements}

This research project was founded by Guangxi Science and Technology Bureau (1222003-2-4 and 10100014-5) and Guangxi Government Senior Scientist Foundation (2011B020).

Received: 15 January 2014 Accepted: 25 April 2014

Published: 29 April 2014 


\section{References}

1. Hattermann K, Schmmitt C, Soike D, Mankertz A: Cloning and sequencing of duck circovirus (DuCV). Arch Virol 2003, 148:2471-2480.

2. Fringuelli E, Scott AN, Beckett A, McKillen J, Smyth JA, Palya V, Glavits R, Ivanics E, Mankertz A, Franciosini MP, Todd D: Diagnosis of duck circovirus infections by conventional and real-time polymerase chain reaction tests. Avian Pathol 2005, 34:495-500.

3. Chen C, Wang P, Lee M, Shien J, Shieh H, Ou S, Chen C, Chang P: Development of a polymerase chain reaction procedure for detection and differentiation of duck and goose circovirus. Avian Dis 2006, 50:92-95.

4. Banda A, Galloway-Haskins RI, Sandhu TS, Schat KA: Genetic analysis of a duck circovirus detected in commercial Pekin ducks in New York. Avian Dis 2007, 51:90-95.

5. Zhang X, Jiang S, Wu J, Zhao Q, Sun Y, Kong Y, Li X, Yao M, Chai T: An investigation of duck circovirus and co-infection in Cherry Valley ducks in Shandong Province, China. Vet Microbiol 2009, 133(3):252-256.

6. Xie L, Xie Z, Zhao G, Liu J, Pang Y, Deng X, Xie Z, Fan Q: Complete Genome Sequence Analysis of a Duck Circovirus from Guangxi Pockmark Ducks. J Virol 2012, 86(23):13136-13136.

7. Soike D, Albrecht K, Hattermann K, Schmitt C, Mankertz A: Novel circovirus in mulard ducks with developmental and feathering disorders. Vet Rec 2004, 154:792-793.

8. Wan C, Fu G, Shi S, Cheng L, Chen H, Peng C, Lin S, Huang Y: Epidemiological investigation and genome analysis of duck circovirus in Southern China. Virol Sin 2011, 26(5):289-296

9. Liu SN, Zhang XX, Zou JF, Xie ZJ, Zhu YL, Zhao Q, Zhou EM, Jiang SJ: Development of an indirect ELISA for the detection of duck circovirus infection in duck flocks. Vet Microbio/ 2010, 145(1):41-46.

10. Wan C, Huang Y, Cheng L, Fu G, Shi SH, Chen H, Peng C, Lin F, Lin J: The development of a rapid SYBR Green I-based quantitative PCR for detection of Duck circovirus. Virol J 2011, 8:465

11. Halami MY, Nieper $H$, Müller $H$, Johne R: Detection of a novel circovirus in mute swans (Cygnus olor) by using nested broad-spectrum PCR. Virus Res 2008, 132:208-212.

12. Notomi T, Okayama H, Masubuchi H, Yonekawa T, Watanabe K, Amino N, Hase T: Loopmediated isothermal amplification of DNA. Nucleic Acids Res 2000, 28:E63.

13. Xie ZX, Tang Y, Fan Q, Liu JB, Pang YS, Deng XW, Xie ZQ, Peng Y, Xie LJ, Khan Ml: Rapid detection of Group I avian adenoviruses by a Loop-mediated isothermal amplification. Avian Dis 2011, 55:575-579.

14. Enomoto Y, Yoshikawa T, Ihira M, Akimoto S, Miyake F, Usui C, Suga S, Suzuki K, Kawana T, Nishiyama Y, Asano Y: Rapid diagnosis of herpes simplex virus infection by a loopmediated isothermal amplification method. J Clin Microbiol 2005, 43:951-955.

15. Peng Y, Xie ZX, Lie JB, Peng YS, Deng XW, Xie ZQ, Xie LJ, Fan Q, Feng JX, Khan Ml: Visual detection of $\mathrm{H} 3$ subtype avian influenza viruses by reverse transcription loop-mediated isothermal amplification assay. Virol Jour 2011, 8:1-10.

16. Nemoto $M$, Imagawa $H$, Tsujimura $K$, Yamanaka $T$, Kondo $T$, Matsumura T: Detection of equine rotavirus by reverse transcription loop-mediated isothermal amplification (RT-LAMP). J Vet Med Sci 2010, 72:823-826.

17. Rovira A, Abrahante J, Murtaugh M, Munoz-Zanzi C: Reverse transcription loop-mediated isothermal amplification for the detection of Porcine reproductive and respiratory syndrome virus. J Vet Diagn Invest 2009, 21:350-354.

18. Xie Z, Fan Q, Liu J, Pang Y, Deng X, Xie Z, Xie L, Khan M: Reverse transcription loop-mediated isothermal amplification assay for rapid detection of Bovine Rotavirus. BMC vety res 2012, 8(1):133.

19. Fan $Q$, Xie Z, Xie L, Liu J, Pang Y, Deng X, Xie Z, Peng Y, Wang X: A reverse transcription loop-mediated isothermal amplification method for rapid detection of bovine viral diarrhea virus. J Virol Methods 2012, 186(1-2):43-48.

20. Xie Z, Xie L, Pang Y, Lu Z, Xie Z, Sun J, Deng X, Liu J, Tang X, Khan M: Development of a real-time multiplex PCR assay for detection of viral pathogens of penaeid shrimp. Arch Virol 2008, 153:2245-2251.

21. Wang D, Xie X, Zhang D, Ma G, Wang X, Zhang D: Detection of duck circovirus in China: a proposal on genotype classification. Vet Microbiol 2011, 147(3):410-415.
22. Tomita N, Mori Y, Kanda H, Notomi T: Loop-mediated isothermal amplification (LAMP) of gene sequences and simple visual detection of products. Nat Protoc 2008, 3:877-882.

23. Woźniakowski G, Kozdruń W, Samorek-Salamonowicz E: Loop-mediated isothermal amplification for the detection of goose circovirus. Virol J 2012, 9(1):1-11.

doi:10.1186/1743-422X-11-76

Cite this article as: Xie et al:: A loop-mediated isothermal amplification assay for the visual detection of duck circovirus. Virology Journal 2014 11:76.

\section{Submit your next manuscript to BioMed Central and take full advantage of:}

- Convenient online submission

- Thorough peer review

- No space constraints or color figure charges

- Immediate publication on acceptance

- Inclusion in PubMed, CAS, Scopus and Google Scholar

- Research which is freely available for redistribution

Submit your manuscript at www.biomedcentral.com/submit
C Biomed Central 